\title{
Metastatic Implantation of Head and Neck Squamous Cell Cancer at PEG Tube Site Exit- An Unusual Relapse Site: A Case Report and Review of Literature
}

\author{
${ }^{1}$ Vijay Palwe, ${ }^{2}$ Kaustav Talpatra, ${ }^{3}$ Umesh Mahantshetty, ${ }^{4}$ Seethalaxmi Viswanathan \\ ${ }^{1}$ Senior Registrar, Department of Radiation Oncology, Tata Memorial Hospital, Mumbai, Maharashtra, India \\ ${ }^{2}$ Consultant, Department of Radiation Oncology, KD Ambani Hospital and Medical Research Center, Mumbai, Maharashtra, India \\ ${ }^{3}$ Associate Professor, Department of Radiation Oncology, Tata Memorial Hospital, Mumbai, Maharashtra, India \\ ${ }^{4}$ Associate Professor, Department of Pathology,Tata Memorial Hospital, Mumbai, Maharashtra, India
}

Correspondence: Umesh Mahantshetty, Associate Professor, Department of Radiation Oncology, Tata Memorial Hospital Mumbai-400012, Maharashtra, India, Phone: 91-22-24177000, Ext: 7168, Fax: 91-22-24146937, e-mail: drumeshm@ gmail.com

\begin{abstract}
Background: The placement of percutaneous endoscopic gastrostomy (PEG) tubes is a common procedure in patients with head and neck cancer who require adequate nutrition because of the inability to swallow before or after surgery and adjuvant therapies. A potential complication of percutaneous endoscopic gastrostomy tubes is the metastatic spread from the original head and neck tumor to the gastrostomy site.

Methods: This is a case of a 55-year-old male with a (cT4N3M0) stage IV squamous cell carcinoma of the oropharynx who underwent percutaneous endoscopic gastrostomy tube placement prior to commencement of definitive chemoradiation therapy and 7 months thereafter developed metastatic spread to the gastrostomy site. Tumor was treated with radiation therapy. A review of the published literature regarding the subject is done. The pull-through method of gastrostomy tube placement had been used in our patient as well as in the majority of the other cases reviewed in the literature.

Conclusions: There is a small but definite risk for tumor implantation in the gastrostomy site when using the pull technique in patients with active head and neck cancer. The direct implantation of tumor through instrumentation is the most likely explanation for metastasis; however, hematogenous seeding is also a possibility. Careful assessment of the oropharynx and hypopharynx before PEG tube placement and the use of alternative techniques for enteral access in patients with untreated or residual malignancy are recommended to minimize this risk.

Keywords: PEG site metastasis, Tumor implantation, Head and neck cancer.
\end{abstract}

\section{INTRODUCTION}

Patients with head and neck cancers frequently present with or will develop odynophagia or dysphagia during the disease process, either as a presenting symptom or after treatment with chemotherapy, radiotherapy or surgical resection. Most of these patients would undergo nasogastric tube placement for maintaining hydration and improving nutritional status. Nasogastric feeding may be contraindicated in some patients because of gastrointestinal reflux, aspiration, nasal ulceration and frequent tube blockage. To overcome these, percutaneous endoscopic gastrostomy (PEG) tube placement is widely accepted alternate route for enteral alimentation. ${ }^{1-5}$ Cancer metastatic to a PEG tube exit is a rare but serious complication of this procedure ${ }^{6-14}$ We report a case of a patient who underwent PEG placement prior to definitive chemoradiation for squamous cell carcinoma of right tonsil. Eight months post PEG closure (15 months postchemoradiotherapy), patient presented with an isolated biopsy proven metastasis at endoscopic gastrostomy (PEG) site.

\section{CASE REPORT}

A 55-year-old male presented to our hospital with complaints of difficulty in swallowing and swelling in right side of neck since 2 months. Clinical examination and MR imaging of face and neck suggested neoplastic involvement of right tonsil extending to right base of tongue and right floor of mouth along with a conglomerate nodal mass measuring $5.5 \times 4 \times 4 \mathrm{~cm}$ at right level II/III. This was confirmed by biopsy from the lesion, which suggested squamous cell carcinoma and fine needle aspiration cytology (FNAC) from neck node showed metastatic squamous carcinoma cells. With diagnosis of cT4N3M0 right tonsil carcinoma, patient was planned for definitive concomitant chemoradiation. Prior to starting of chemoradiation, patient underwent PEG tube placement (24 Fr Wilson Cook PEG tube) by pull through technique for enteral nutrition to maintain his nutritional status. Patient was treated with radical intent with external radiation to bilateral face and neck with Co $60 \gamma$ rays to a total dose of $66 \mathrm{~Gy}$ in 33 fractions with reducing 
field technique using customized tissue compensators along with 6 cycles of concurrent chemotherapy injection Cisplatin $30 \mathrm{mg} / \mathrm{m}^{2}$. Patient completed treatment with good compliance and tolerated chemoradiation well with grade II skin reactions and grade II mucositis. Patient partially responded to this treatment who, on first follow-up after 2 months, was investigated with CECT scan of the face and neck showed no evidence of any residual soft tissue mass in the oropharynx or tonsillar region but the lymph nodal mass on the right side of the neck at level II of size $3.7 \times$ $2.0 \times 4.2 \mathrm{~cm}$ persisted though decreased in size. Patient underwent right radical neck dissection for the residual lymph nodal mass. The PEG tube was removed after surgery (7 months after its placement).

Subsequently, on follow-up 8 months after surgery (15 months after placement of PEG tube) patient presented with complaints of painful ulcer and swelling on anterior abdominal wall, at the PEG site since 2 months. On clinical examination, patient was locoregionally controlled but had an ulcerative growth at the gastrostomy site that was friable and bleeding (Fig. 1). On further investigations, upper gastrointestinal endoscopy revealed a large deep

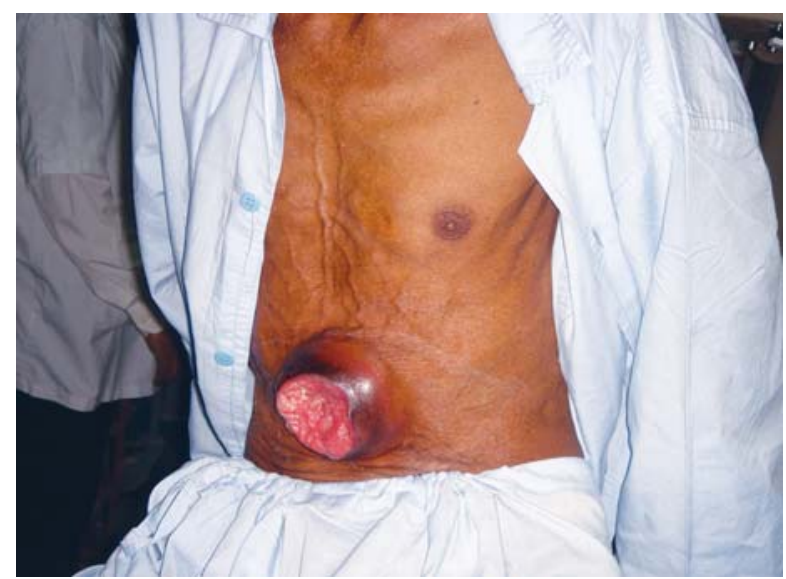

Fig. 1: Clinical photograph of patient with PEG exit site metastasis

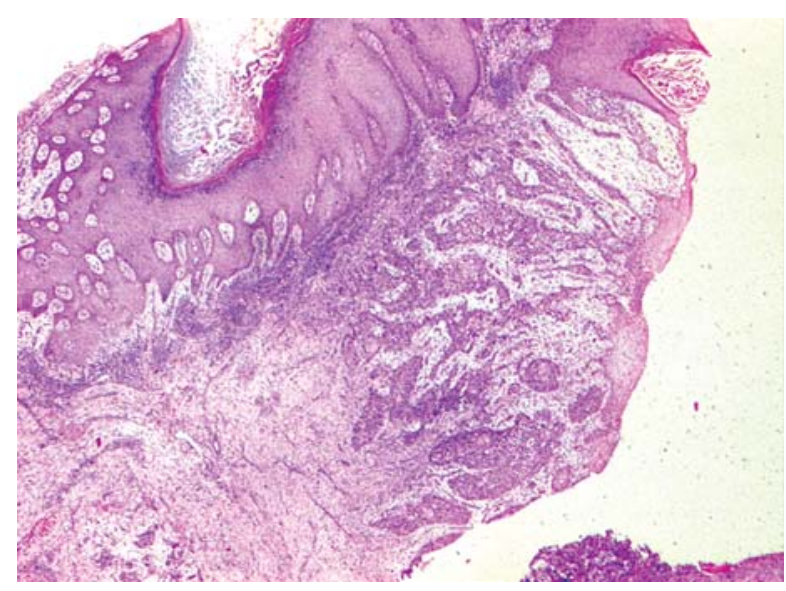

Fig. 2: Section from the stoma site showing skin beneath which are seen nests of keratinizing squamous carcinoma $(H \& E \times 40)$ ulceroinfiltrative growth in the anterior wall of stomach in mid and distal body, rest of stomach was unremarkable. Biopsy of the mass was suggestive of metastatic deposits of squamous carcinoma (Fig. 2). Abdominal computed tomography (CT) showed inhomogenous, lobulated, contrast enhancing mass around the gastrostomy site at the anterior abdominal wall and the thickness of the gastric wall was relatively increased (Fig. 3). The patient refused to undergo any surgery and was referred to us for palliative radiation therapy. He received palliative external radiation to anterior abdominal wall with Co $60 \gamma$ rays to a total dose of $20 \mathrm{~Gy}$ in 5 fractions (4 Gy/fraction/day) with direct anterior portal. He was under close observation and on regular follow-up for the assessment of response to the treatment. A significant reduction in the size of the mass was obtained at 2 months postradiation. Patient refused for further treatment and died within 2 months due to progressive disease.

\section{DISCUSSION}

Gauderer et al first described the technique of percutaneous endoscopic gastrostomy (PEG) in $1980 .{ }^{1}$ PEG tubes are usually placed using the 'pull technique' or 'push technique'. ${ }^{1,2}$ In both these techniques, the tube is pulled or pushed through the oropharynx into position in the stomach by an endoscopically placed guide wire, which runs from mouth to the stomach and through the anterior abdominal wall. In pull-through technique, an angiocatheter is introduced through the abdominal wall into the insufflated stomach under direct visualization. A wire is then passed through the angiocatheter, snared endoscopically, and pulled through the patient's mouth. The gastrostomy tube is then attached to the end of the wire and pulled back through the mouth and esophagus into the stomach and out through the abdominal wall. In push-through or introducer technique uses the Seldinger method to directly place the tube through the abdominal wall into the stomach that has been insufflated by way of the esophagus. ${ }^{2}$ This technique does not require

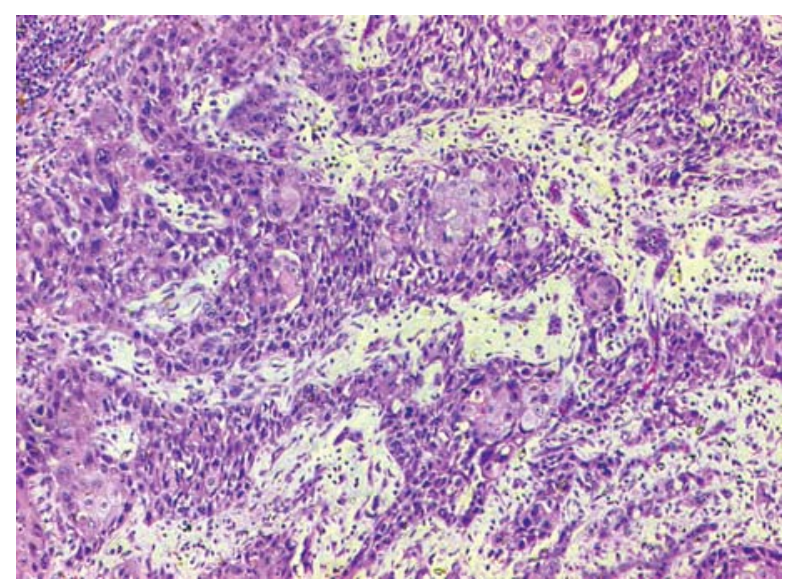

Fig. 3: Higher power view of the same tumor $(H \& E \times 100)$ 
passage of the gastrostomy tube over the pharynx. Complications of percutaneous endoscopic gastrostomy are relatively uncommon, but include local infection, hemorrhage, dislodgment, peritonitis, bowel perforation and aspiration pneumonia ${ }^{15}$ Another rare complication that appears to be becoming more prevalent is the metastatic implantation of tumor at the PEG tube site. ${ }^{6,14}$ The first case of gastric and abdominal wall metastasis secondary to PEG placement in a patient with head and neck cancer was reported in 1989. ${ }^{6,15}$ Since the introduction of this technique, there have been at least 23 case reports of tumor seeding at the gastrostomy site. The mode of tumor spread to the gastrostomy site remains controversial and unproven. However, most authors agree that one or more of three different mechanisms may play role in development of PEG site metastasis. Direct translocation of malignant cells from a primary tumor of the upper aerodigestive tract to the PEG tube exit site implicates surgical instruments used in the procedure as the mechanism of iatrogenic spread. ${ }^{16,17} \mathrm{~A}$ second theory involves desquamation of malignant cells into the gastrointestinal tract with resultant distal implantation at the surgically disturbed PEG tube site. ${ }^{18,19}$ The third mechanism, hematogenous spread, is the well-established route by which malignant cells penetrate the circulatory system and travel to a site distant from the primary disease. ${ }^{20}$ The longer the patient survives after treatment, the greater the likelihood of distant metastatic disease developing. The malignant seeding of a PEG site by exfoliated tumor cells is similar to the favored mechanism of direct implantation. The theory requires that malignant cells at periphery of an upper aerodigestive tract tumor becomes dislodged, swallowed, and remain viable within the gastric environment until they happen on the disturbed gastric mucosa or granulation tissue at the PEG site. One can speculate that proton pump inhibitors may predispose to implantation by suppression of acid secretion, producing a more favorable environment for tumor implantation and growth. ${ }^{21}$ There are at least 23 cases of tumor implantation to a PEG site reported in the literature. The interval from the procedure to development of metastasis ranged from 3 to 16 months. The most common cancer type is squamous cell cancer, although one case of PEG site metastasis of esophageal adenocarcinoma was reported. ${ }^{22}$

The phenomenon of metastasis to PEG sites appears to be a rare event, given the number of cases reported, compared with the number of procedures performed per year. However, caution should be used by the endoscopist at the time of the procedure, and techniques should be used so as not to disrupt the tumor bed, particularly when gross residual disease is present at the primary site. ${ }^{23,24}$

PEG placement by the pull method appears to remain the preferred or standard procedure for patients with head and neck cancer in spite of the overwhelming evidence of not to use this method. Careful assessment of the oropharynx and hypopharynx before PEG tube placement and consideration of alternative techniques in feeding tube placement, such as radiologic percutaneous gastrostomy or laparoscopic gastrostomy, delaying the PEG tube procedure until after tumor resection could minimize the risk of translocation of malignant cells to the skin site. Measures should include treatment of the squamous cell carcinoma before instrumentation of the upper aerodigestive tract, enteral access procedures that do not contact the area of the malignancy, such as laparoscopic or open gastrostomy techniques, or the 'push' method of PEG tube placement.

We believe that PEG site metastases represent an iatrogenic complication of the 'pull' technique of PEG placement when used in patients with head and neck cancer though rare in occurrence.

\section{CONCLUSION}

This case reports our experience with a case of head and neck squamous cell carcinoma metastatic to a PEG tube site. Cancer metastasis to the abdominal wall should be considered in patients with unexplained lesions at the PEG site. Biopsy samples should be obtained from any suspicious skin changes around the PEG tube to distinguish metastases from routine exophytic granulation tissue that often develops from PEG sites. Development of abdominal wall metastasis carries a poor prognosis for survival. This potential complication should be discussed as part of the informed consent, particularly if a pull-through technique for PEG tube placement is to be used.

\section{REFERENCES}

1. Gauderer ML, Ponsky JL, Izant RJ. Gastrostomy without laparotomy: A percutaneous endoscopic technique. J Paediatr Surg 1980;15:872-75.

2. Russell TR, Brotman M, Norris F. Percutaneous gastrostomy: A new simplified and cost-effective technique. Am J Surg 1984;148:132-37.

3. Ruppin H, Lux G. Percutaneous endoscopic gastrostomy in patients with head and neck cancer. Endoscopy 1988;18: 149-52.

4. Mamel J. Percutaneous endoscopic gastrostomy. Am J Gastroenterol 1989;84:703-09.

5. Safidi BY, Marks JM, Ponsky JL. Percutaneous endoscopic gastrostomy. Gastrointest Endosc Clin N Am 1998;8:551-68.

6. Alagaratnam TT, Ong GB. Wound implantation: A surgical hazard. Br J Surg 1977;64:872-75.

7. Sharma P, Berry SM, Wilson K, Neale H, Fink AS. Metastatic implantation of an oral squamous cell carcinoma at a percutaneous endoscopic gastrostomy site. Surg Endosc 1994;8:1232-35.

8. Thorburn D, Karim SN, Souter DS, Mills PR. Tumour seeding following percutaneous endoscopic gastrostomy placement in head and neck cancer. Postgrad Med J 1997;73:430-32.

9. Lee DS, Mohit-Tabatabai M, Rush BF, Levine C. Stomal seeding of head and neck cancer by percutaneous endoscopic gastrostomy tube placement. Ann Surg Oncol 1995;2:170-73. 
10. Schneider AM, Loggie BW. Metastatic head and neck cancer to the percutaneous endoscopic gastrostomy exit site: A case report and review of the literature. Am Surg 1997;63:481-86.

11. Douglas JG, Koh W, Laramore GE. Metastasis to a percutaneous gastrostomy site from head and neck cancer: Radiobiologic considerations. Head Neck 2000;22:826-30.

12. Robert Todd Adelson. Metastatic head and neck carcinoma to a percutaneous endoscopic gastrostomy site 14 February 2005 in Wiley InterScience.

13. Ian R Daniels. Port-site tumour recurrence of oral squamous carcinoma following percutaneous endoscopic gastrostomy: A lesson to be aware of. World Journal of Surgical Oncology 2006

14. Preyer S. Gastric metastasis of squamous cell carcinoma of the head and neck after percutaneous endoscopic gastrostomy: Report of a case. Endoscopy 1989;21:295.

15. Nord J. Complications of laparoscopy. Endoscopy 1992;24: 693-700.

16. Fidler I. Molecular biology of cancer: Invasion and metastasis.In: DeVita V (Jr), Hellman S, Rosenberg S (Eds). Cancer: Principles and practice of oncology. Philadelphia: Lippincott-Raven (8th ed), 2008;119-36.

17. Murthy SM, Goldschmidt RA, Rao LN, Ammirati M, Buchmann T, Scanlon EF. The influence of surgical trauma on experimental metastasis. Cancer 1989;64:2035-44.
18. Tubiana M, Malaise EP. Growth rate and cell kinetics in human tumours: Some prognostic and therapeutic implications. In: Symington T, Carter R (Eds). Scientific foundations of oncology. Chicago: Year Book 1976;126-36.

19. Tannock IF. Biology of tumor growth. Hosp Pract 1983;18: 81-90.

20. Liotta L, Kleinerman J, Saidel G. The significance of hematogenous tumor cell clumps in the metastatic process. Cancer Res 1976;36:889.

21. Irma Cruz, Jay J Mamel, Patrick G Brady, Meg Cass-Garcia. Incidence of abdominal wall metastasis complicating PEG tube placement in untreated head and neck cancer. RN Gastrointest Endosc 2005;62:708-11.

22. Peghini P, Guaouguao N, Salcedo J, et al. Implantation metastasis after PEG: Case report and review. Gastrointest Endosc 2000;51:480-84.

23. Urban K, Terris D. Percutaneous endoscopic gastrostomy (PEG): Indications and technique. Operative Techniques OtolaryngolHead Neck Surg 1997;8:77-84.

24. Santos P, McDonald J. Percutaneous endoscopic gastrostomy: Avoiding complications. Otolaryngol Head Neck Surg 1999;120:195-99. 